\title{
Exploration of the Flipped Classroom Teaching Model
}

\author{
Yu Ma \\ Wuxi Vocational College of Science and Technology Wuxi, 214028 Jiangsu, China \\ 362114873@qq.com
}

\begin{abstract}
Keywords: The Flipped Classroom; Teaching model; Problems
\end{abstract}
\begin{abstract}
In the novel teaching model of the Flipped Classroom, the teaching sequence of transferring and internalizing knowledge is completely reversed. Before class, the knowledge is transferred to students using modern information technologies. In class, the requirement of the internalization of knowledge is reached through teacher explanations, student group discussions, etc. According to the changes in teaching models, the various elements of teaching will also change. The purpose of this paper is to try to construct a Flipped Classroom teaching model that suits the actual situation of the classroom based on the characteristics of the Flipped Classroom, and to analyze some problems in the process of implementation in order to provide a new idea for the innovation and reform of the current teaching model.
\end{abstract}

\section{Introduction}

In 2011, Salman Khan proposed in TED: Many students watch the teaching videos of related courses of Khan Academy before class and finish homework on their own. When encountering problems, they search the Internet for information and communicate with teachers and classmates. This teaching model is exactly the opposite to the traditional one and is defined as the Flipped Classroom.1 Since then, "the Flipped Classroom" has become the focus of educators at home and abroad. At present, more and more schools in China have applied the Flipped Classroom to teaching practice and have received good results. The purpose of this paper is to try to construct a Flipped Classroom teaching model that suits the actual situation based on the definition and the basic characteristics of the Flipped Classroom, and to analyze some problems in the process of implementation in order to provide a new idea for the innovation and reform of the current teaching model.

\section{The Definition and the Characteristics of the Flipped Classroom}

Knowledge transferring and internalizing are two important stages in the traditional teaching process. Knowledge transferring mainly refers to teachers deliver information to students in classroom activities. After class, students achieve the requirement of internalization of knowledge by completing homework and practice. In the Flipped Classroom, the process is completely reversed. Before class, the knowledge is transferred to students using modern information technologies. In class, the requirement of the internalization of knowledge is reached through teachers explanations, student group discussions, etc. According to the changes in teaching models, the various elements of teaching will also change.

The role of teachers is changed. In the traditional teaching model, the teacher is the manager in the classroom and the knowledge imparter who explains the knowledge and students passively accept the knowledge. In the flipping classroom teaching model, the role of teachers is transformed into the instructor of self-learning for students and plays a facilitating role in the external environment. When students need help in self-learning process, teachers need to provide them with timely external support. Therefore, teachers provide strong support for students to use resources, receive processing information and so on. In class, teachers design teaching activities to promote students' internalization and use of knowledge. After the completion of the stage learning tasks, teachers promptly check and give feedback to students on the mastery of knowledge, so that they can more accurately conduct self-evaluation in order to better adjust and promote the next stage 
learning.

The role of students is changed. With the continuous development of information technology, the large-scale popularity of the Internet, there are more and more diverse ways and means to obtain knowledge. Students are transformed from passive acquisition of knowledge in traditional classroom to active knowledge researchers in new type of classroom. With the deep integration of information technology and classroom teaching, teachers use various online platforms to effectively provide students with a variety of learning resources. Students learn, think, explore and solve problems independently, and continuously communicate with classmates and teachers based on the problems encountered in the learning, in order to fully understand, grasp and apply knowledge. The Flipped Classroom is a flexible and diverse classroom that continuously expands the depth and breadth of knowledge in which students become the protagonists of learning.

The teaching model is changed. Another important feature of the Flipped Classroom that is different from the traditional one is that they reduce the time of teachers' lectures and place more time on communication between teachers and students to solve problems while allowing students to meet learning requirements in interactive collaboration. The content which was taught in the traditional class is taught before class. Based on students' self-learning, the interaction between teachers and students and students and students is enhanced. This teaching model maximizes teaching effectiveness by maximizing self-learning before class. As the same time, when preparing teaching contents, teachers should consider how to make full use of the limited time in class to complete the process of internalizing knowledge.

\section{Teaching Model Design of the Flipped Classroom}

In the Flipped Classroom, modern information technology and self-directed learning provide students with flexible, personalized and collaborative learning environment that helps students complete self-learning efficiently2. Prof. Robert Talbert of Franklin Institute in the United States applied the Flipped Classroom in teaching and achieved good teaching results. After many years of practical accumulation, he summed up the structural model of teaching practice in the Flipped Classroom (see Table 1). 
Table 1. The structural model of the Flipped Classroom of Robert Talbert

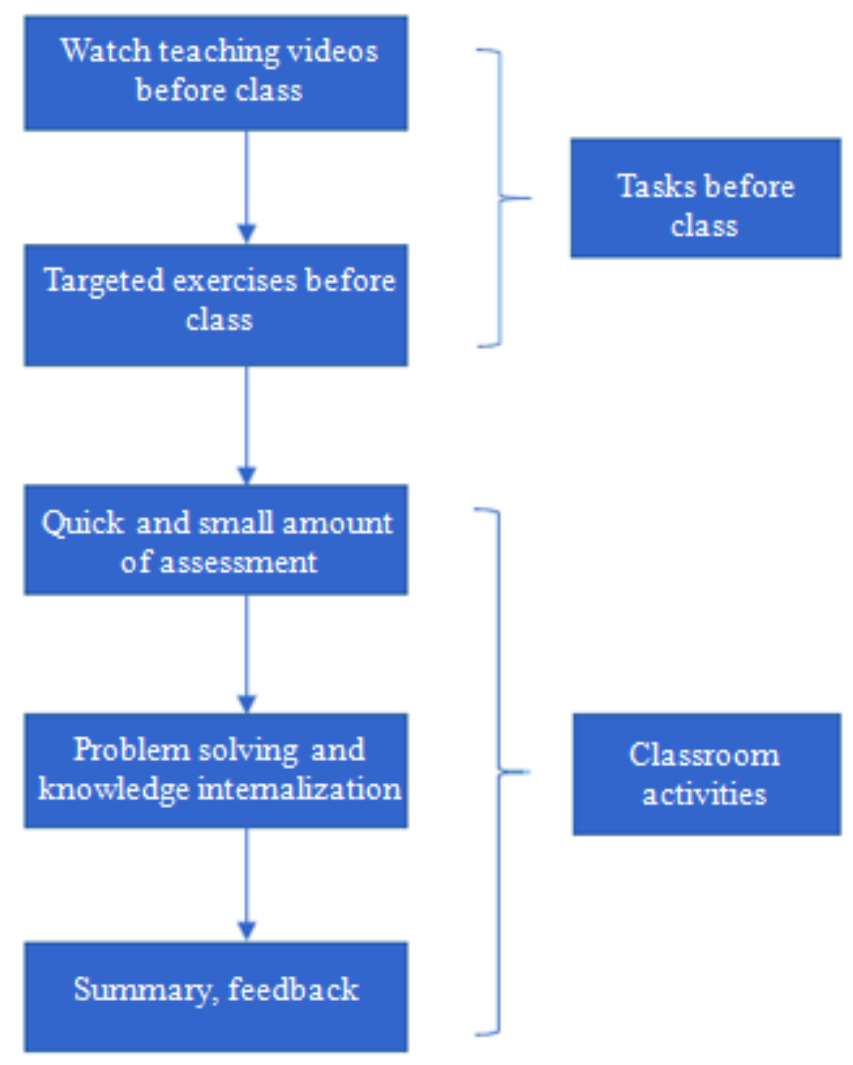

Source: Robert Talbert. Inverting the Linear Algebra Classroom. http:// prezi.com/dz0rbkpy6tam/inverting-the-linear-algebra-classroom

In addition, the theory of individual constructivism believes that learning is the process by which individuals build their own knowledge. Learners are active explorers rather than passive recipients. When receiving external information, they must actively process external information. Each learner add his own understanding of new information based on the existing experience. Therefore, learning is not simply the accumulation of information, but also includes the changes of ideas and reconstruction due to the interaction of new and existing experiences.

The learning process is not simplicity the process of inputting, storing and extracting information, it is also the collision and integration of learners' existing and new experiences. 3

Based on the above, the author constructs a flipped classroom teaching model based on the actual teaching situation (see Table 2). Before class, teachers use modern information technology to reintegrate and optimize the various teaching resources needed in learning process. Teachers use the interactive platform to identify the focuses of each class to make students clear the learning objectives, so as to create a good environment for students to learn independently before class and interactive learning in class. At the same time, students use the Internet to break through the limitations of time and space in self-learning before class, and independently select online video resources released by teachers at any time and any place. At the same time, students should be good at discovering and raising questions.

In classroom activities, teachers should use educational information technology to give full play to the individuality of student learning, effectively create an interactive classroom learning environment and complete the internalization of knowledge. First of all, teachers sum up the common problems based on the analysis of the teaching and learning difficulties and the students' watching teaching videos and the problems raised by students before class. According to the nature of problems, students will be grouped to discuss these problems. The number of students of each 
discussion group will be 3-5. Then, according to the individual characteristics of students, they will perform assignments within the group. Each team member will address a certain aspect of problems to conduct information collection and self-discovery. Finally, group members conduct interactive research, cooperation and exchange on the available information to solve problems.

After independent exploration and cooperative learning, each group completes the summary report or PPT results display in a group as a unit. In classroom activities, teachers can arrange time for students to report and communicate their learning results. The presentation of results are various and methods of presentation can also be flexible. In addition to reporting directly in classroom, students can also record and upload their own videos to exchange platforms. Teachers and students can comment and discuss on the exchange platform by watching videos. In addition, the Flipped Classroom evaluation system is completely different from the traditional one. The traditional evaluation methods are one-sided, often valuing students' learning results and ignoring their efforts in learning process. The Flipped Classroom does not only pay attention to the evaluation of learning results, but also pays more attention to the evaluation of students' learning process. Of course, the content of evaluation is also multifaceted, such as: the performance of self-learning before class, the interactive situation in communication platform, the performance in group learning, the presentation of results, etc. The evaluation method can be more objective and comprehensively feedback on students' learning situation.

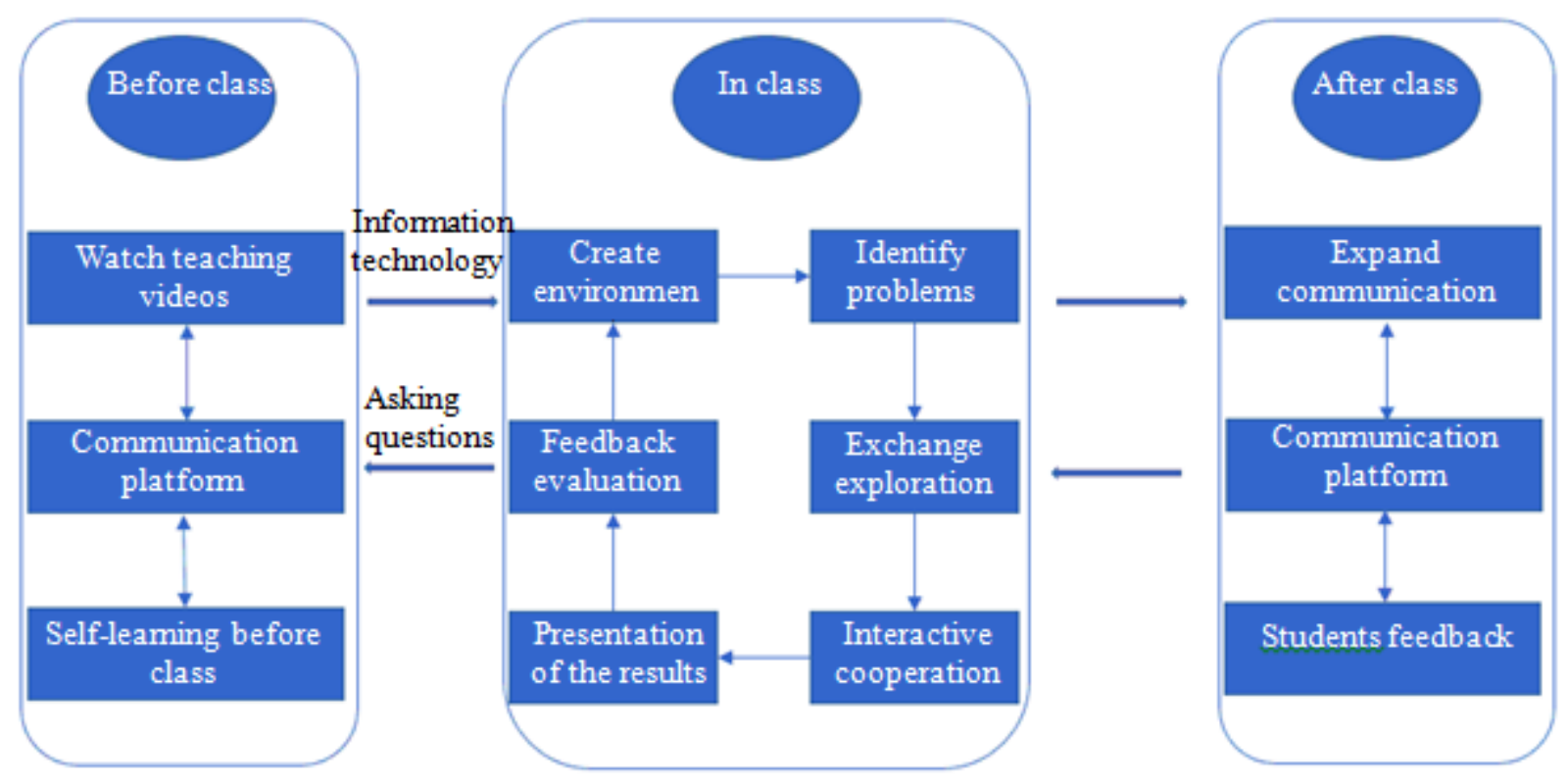

Table 2. Teaching model design of the Flipped Classroom

\section{Problems That Should Be Solved in the Flipped Classroom}

Set up network platform to provide technical support. Teachers' production of teaching videos, students' collection of network resources and watching teaching resources are inseparable from the support of computer hardware and software. One of the key factors in the successful implementation of the Flipped Classroom is whether they have information technology protection. In implementing the Flipped Classroom, schools should provide technical support and equipment support through various means, such as building digital teaching platform and gigabit campus network, updating hardware facilities, expanding student computer room and equipping professional technicians. In addition, the interaction between teachers and students after class is an important factor in the success of the Flipped Classroom. Using information technology to build a 
network platform for teachers and students is crucial to build a personalized and collaborative learning environment. Through the Internet platform, uploading and downloading of teaching resources, online watch, independent exploration, online communication, answering questions and so on can be achieved.

Improve professional and information skills of teachers. Teachers are one of the key elements in the Flipped Classroom which is a new type of teaching model. In the implementation process of the Flipped Classroom, the quality of teaching video recording, timely communication guidance to students, reasonable organization of classroom activities, objective and impartial teaching feedback, etc. have profound impact on the effectiveness of the effective implementation of the Flipped Classroom. Therefore, it is imperative to strengthen the training of education informatization and improve the professional skills of teachers. With the help of professional and technical personnel, teachers can record teaching videos that are lively and attractive to students, and can be good at guiding students on online platform to actively communicate and interact, mobilizing students' enthusiasm and initiative, and inspiring students' curiosity and exploratory to knowledge, which provides an important guarantee for the smooth implementation of the Flipped Classroom.

Improve Students' self-learning ability and Information literacy. Before class, students watch teaching videos, complete related exercises by themselves, find out problems and search for information on the Internet, summarize and explore problems, and then discuss and solve problems with teachers and classmates in the classroom. The implementation of these links is inseparable for the self-learning ability and a solid information literacy of students. Therefore, teachers should consciously and continuously improve students' self-learning ability and information literacy. Only by possessing these abilities can they learn to use the Flipped Classroom and can teach effectively conduct each teaching link of the novel teaching model.

\section{Conclusion}

Although the Flipped Classroom has been increasingly used by educators, there are still many problems in practice. In order to solve these problems, we should continue to explore and summarize in practice, so that every link in the new classroom teaching model is constantly perfected and the Flipped Classroom can better serve the teaching activities. In addition, we should follow the trend of national education informatization and use the relevant favorable policies to promote information-based teaching, and strive to provide effective references and lessons for the use and promotion of the Flipped Classroom.

\section{Acknowledgements}

2017 Project of the Philosophy and Social Sciences Research Fund of Jiangsu Higher Education Institutions "Practice and Research of Chinese Traditional Culture in Flipped English Classes in Higher Vocational Colleges" (Project Number: 2017SJB0879); 2017 Jiangsu Provincial Social Education Planning Topic "Study on the Construction Path and Effectiveness of Community Learning Community in Jiangsu Province” (Project Number: JSS-C-2017001).

\section{References}

[1] Zhang Jinlei, (2013). Analysis of Key Factors in Teaching Model of "the Flipped Classroom"[J]. Distance Education in China, 59-64.

[2] Zhang Jinlei, Wang Ying, Zhang Baohui (2012). Research on the Flipped Classroom Teaching Model[J]. Journal of Distance Education, 30(4) , 46 -51. 
[3] Chen Qi, Zhang Jianwei, (1998) Comment on the Essential Meaning of Constructivism Learning View[J]. Journal of East China Normal University (Educational Science Edition), 61-68.

[4] Zhang Yueguo, Zhang Yujiang. A Perspective of "Flipped Classroom"[J]. Information Technology Education in Primary and Secondary Schools, 2012, (3).

[5] The flipped classroom

[EB/OL].[2012-03-16] http://digitalsandbox.weebly.com/flipped-infographic.html.

[6] Meris Stansbury. A first-hand look inside a flipped classroom [EB/OL][2012-03-18] http://www.eschoolnews.com/2012/02/09/afirst-hand-look-inside-a-flipped-classroom

[7] The flipped classroom[EB/OL].[2012-04-12] http://batchgeo.com/map/8a3b1332c605d5384c33f3d2a18ec545

[8] Ministry of Education. Ten Year Development Plan for Education Information (2011-2020) [EB/OL].[2012-05-06] - http://www.edu.cn/zong_he_870/20120330/t20120330_760603_3.s 